\title{
Middle East's synchrotron heads for Jordan
}

Paris

Jordan has been chosen as the proposed host of an international research centre for the Middle East, the organizers of the project announced last week. It is hoped that the new centre will be able to mirror the European Laboratory for Particle Physics (CERN) in stimulating regional research collaboration.

The centrepiece of the facility, to be known as Sesame (Synchrotron Radiation for Experimental Science and Applications in the Middle East), will be an upgraded version of BESSY-1, a decommissioned $0.8 \mathrm{GeV}$ synchrotron now located in Berlin, which is being donated by the German government (see Nature 399, 507-508; 1999).

A team of Russian and Armenian scientists - Russia is one of the 'observers' of the the project - has begun to dismantle BESSY-1, and plans to have it ready for shipping out by September.

The recommendation that Jordan should host the site was made by 11 members of an interim council set up to represent the countries in the region. Final approval will be sought in June from the full interim council.
Armenia was second choice if the project cannot go ahead in Jordan.

Herwig Schopper, former director-general of CERN and president of Sesame's interim council, says that choosing Jordan from the seven candidates was "difficult". But he says that it was "objective and cooperative and that is the point of the project — to bring together different nations and to use science as a catalyst and a tool for peace".

The centre will be operated and supported by its member countries - Armenia, Cyprus, Egypt, Greece, Iran, Israel, Jordan, Morocco, Oman, the Palestinian Authority and Turkey - with support from countries including the United States, Sweden, Germany, Japan, Switzerland, Italy and Russia.

Sesame will be open to scientists from any country in the region or elsewhere. Planned research programmes include structural molecular biology, molecular environmental science, surface and interface science, microelectromechanical devices, X-ray imaging, archaeological microanalysis, materials characterization, and medical applications.

The centre is likely to be the largest modern science facility in the Middle East.
According to Khaled Toukan, president of Al-Balqa' Applied University in Jordan, the country was chosen partly because of its centrallocation.

Although the project has wide backing from the governments of the region, as well as the United Nations Educational, Scientific and Cultural Organization (Unesco), which is overseeing the project, Sesame has yet to raise enough money to build the centre and cover its initial operating costs.

Jordan's King Abdullah II has promised that Jordan will contribute US $\$ 1$ million a year for five years to the centre, leaving the other countries to split the remaining costs.

Schopper estimates that installing and upgrading the synchrotron will cost $\$ 20$ million. Installing and equipping ten beamlines in five years, together with building the facility will require a similar amount, he says. Annual operating costs are estimated at $\$ 3.5$ million.

Funding is sought from the European Union and American peace efforts. "The problem now is the financing," says Schopper. "Now that we have decided on a site I hope we can move ahead." Heather McCabe

\section{Top physicist crosses to Boston in search of like minds}

\section{Boston}

In a move which he himself describes as "curious", the Nobel-prizewinning physicist Sheldon Glashow has revealed that he will leave Harvard University in July to join the nearby but less prestigious Boston University (BU).

Glashow acknowledges that he will be "getting a raise", but insists that money is not a motivating factor. At this stage in his career, he says, he is instead looking for more collegiality. Colleagues point out that he has become isolated intellectually at Harvard, where most theoretical physicists are engaged with string theory, in contrast to Glashow's more phenomenological interests.

"Harvard is at the top. BU is not in that category," admits Glashow. But for that reason, he feels he can have a greater impact at BU. "I hope to devote the years I have left to making BU first-rate, like Harvard. I'm 67 years old and ready for new challenges."

Glashow shared the 1979 Nobel Prize in Physics with Abdus Salam and Steven Weinberg for work that linked electromagnetism and the weak nuclear force. At BU he will be a professor in both physics and a new interdisciplinary programme.

In the latter capacity, Glashow will teach BU undergraduates alongside other Nobel

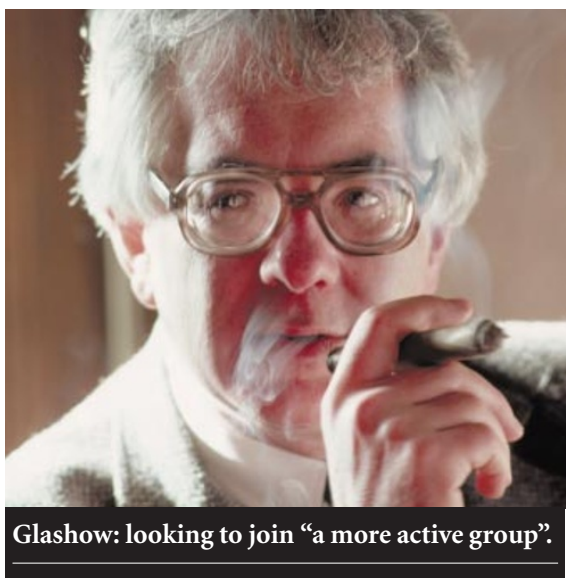

laureates. These include Saul Bellow and Derek Walcott, both winners of the Nobel Prize in Literature, and peace-prizewinner Elie Wiesel.

"Professors in this programme get together frequently, acting in the spirit of how I imagine English universities used to be - or might still be," Glashow says. "You interact with your colleagues more often than seems to be the case at Harvard."

He stresses that he is not disenchanted with Harvard. "In fact, one of the first things I'll do at BU is try to forge closer relations with Harvard and the Massachusetts Institute of Technology.” But
BU has a large group of theorists working in his area of particle physics, which focuses on phenomena that can be measured through experiments or astrophysical observations.

"I'll have more colleagues in this field and be part of a more active group," he says. At Harvard, the physics department has been moving in a different direction. "The last few appointments have been in string theory, which is not my area," he adds.

Lawrence Sulak, chairman of the BU physics department, believes that Glashow became isolated as Harvard moved towards string theory - "an exciting, promising theory which at the moment offers very little opportunity for experimental verification".

Sulak, himself a former member of the Harvard faculty, points out that there is a trend towards string theory at other top university physics programmes. Besides Glashow, "the only other theorist left at Harvard who is active in phenomenology is Sidney Coleman. It's hard to get much crossfertilization with only one colleague.

"You need enough people to get a critical mass. That's when things start to get interesting. I also think Shelly is looking to have more fun in his work." Glashow has been a part-time 'distinguished scientist' at BU since 1984. "He's the godfather here," says Sulak.

Steve Nadis 